J. industr., Med., 1948, 5, 198.

\title{
DUST SAMPLING IN A HAMATITE MINE WITH THE P.R.U. HAND PUMP
}

BY

\author{
H. H. WATSON \\ From the Pneumoconiosis Research Unit (Medical Research Council), Cardiff
}

(RECEIVED FOR PUBLICATION, MAY 3, 1948)

\section{Introduction}

For dust assessment work in the coal-mines of South Wales and elsewhere, the Pneumoconiosis Research Unit of the Medical Research Council has found a hand pump, filter-paper, stain method to be of great value. Particular advantages of the method are the simplicity and portability of the sampling apparatus and the speed with which a large number of samples can be assessed. The sampling apparatus comprises a hand pump, in the head of which is inserted a small piece of white filter-paper. Air is drawn through the paper with the pump, and a "stain" is formed by the dust deposited on the front surface of the paper. The optical density of the stain can be related by suitable calibration to the amount of dust deposited, and hence to the concentration. A photo-electric densitometer is used to measure stain density.

It is likely that the method will be suitable for assessing other dusts that are coloured and that will produce a stain on white filter-paper. Assessment of white dusts collected on black paper may also be possible.

The present paper is an account of a trial in a hæmatite mine, where the dust is brick-red in colour. It was thought that the method might appreciably reduce the labour of sampling and assessment and thus make possible more frequent and comprehensive dust inspections and surveys of the type Craw (1948) has undertaken.

\section{The P.R.U. Hand Pump}

Description of Instrument.-As a full description of the P.R.U. (Pneumoconiosis Research Unit) hand-pump dust-sampling method has been published elsewhere (Watson and Hounam, 1948), it will be described here only briefly.

The hand pump (fig. 1) consists of a brass barrel in which moves a piston, provided with an oiled cupleather, to give a swept volume of about $90 \mathrm{c.cm}$. To the inlet end of the pump is screwed a brass adaptor head. Into this is inserted a small brass hinged-clip which carries a piece of filter paper. The clip is held in position and air-tight seals made by tightly screwing down a sampling nozzle to register with a depression in the top surface of the clip. The underside of the clip seats on a rubber washer, cemented to the adaptor head. When the pump handle is pulled out, air is drawn into the barrel through the filter paper. On the return stroke most of the air within the barrel escapes past the cup-leather and only a small portion back through the paper.

The sampling kit consists of a hand pump and sixty numbered sampling clips, the clips being carried in a slotted wooden carrying box (fig. 1).

Whatman No. 1 filter paper has been found suitable, and squares with sides $1.75 \mathrm{~cm}$. are inserted in the clips before they are sent from the laboratory. A circle of the paper $1 \mathrm{~cm}$. in diameter is exposed by the clip, and it is on this that the dust is deposited.

Laboratory Preparation.-Leaks can occur in the system at a number of points.

(a) Between the walls of the barrel and the cupleather. The leather should be soft and free from wrinkles. Oiling with light machine oil once a week is recommended.

(b) Between the underside of the clip and the rubber washer. If the washer is flat and firmly cemented in position, no trouble should be experienced provided the sampling nozzle is screwed down tightly and the clip has not become distorted.

(c) Between the top (that is, the sampling side) of the clip and the rear end of the nozzle. No leak should occur with clips in good order. A small leak at this point is, in fact, of no consequence under sampling conditions.

A quick check for leaks may be carried out with a clip in position by closing the entrance to the sampling nozzle with the thumb and drawing out the piston to its limit and holding it there. Quite small leaks can be heard in a quiet room. Underground, it is sufficient to note that if the plunger is pulled out with the nozzle closed, it returns immediately to the " in " position. It 


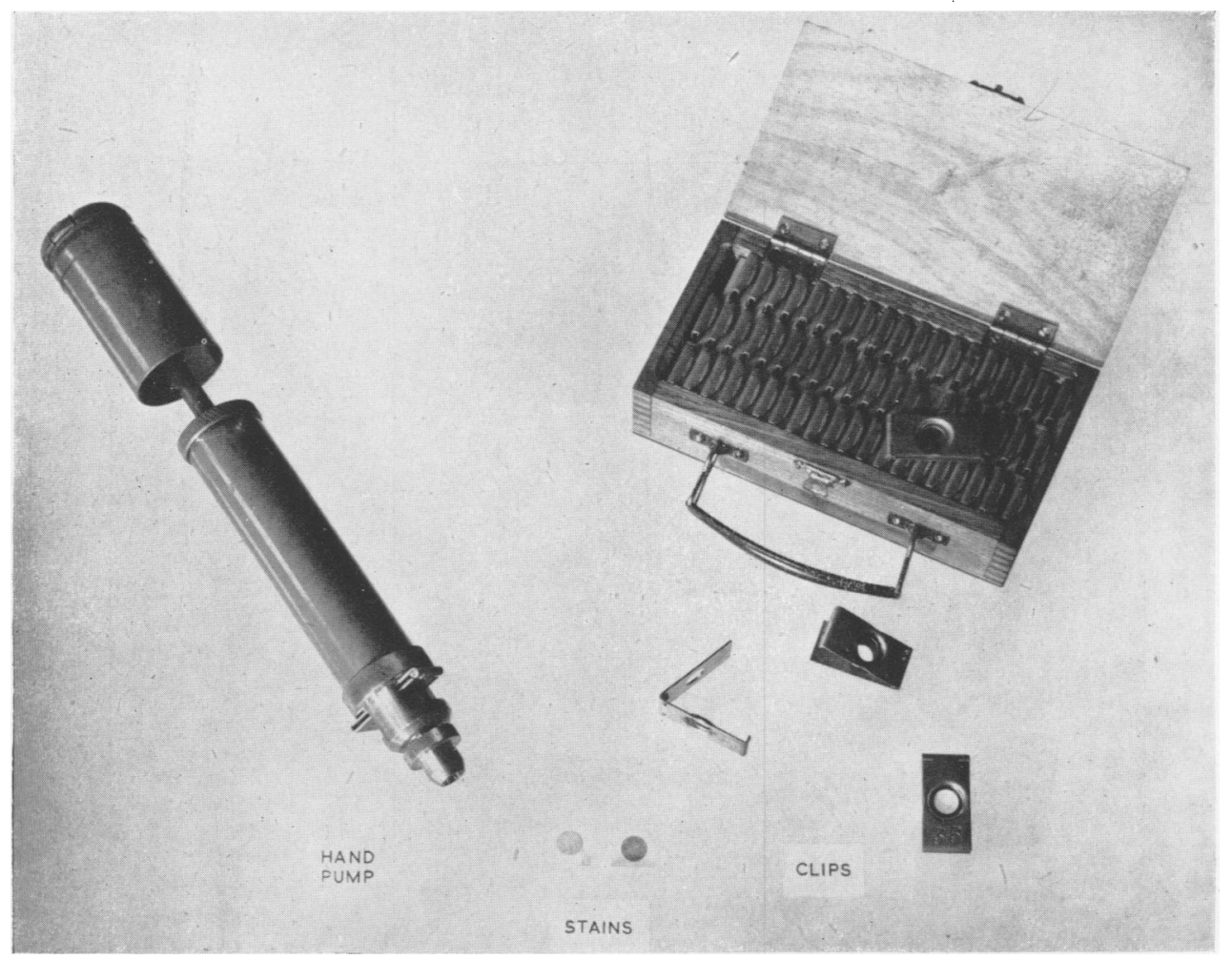

Fig. 1

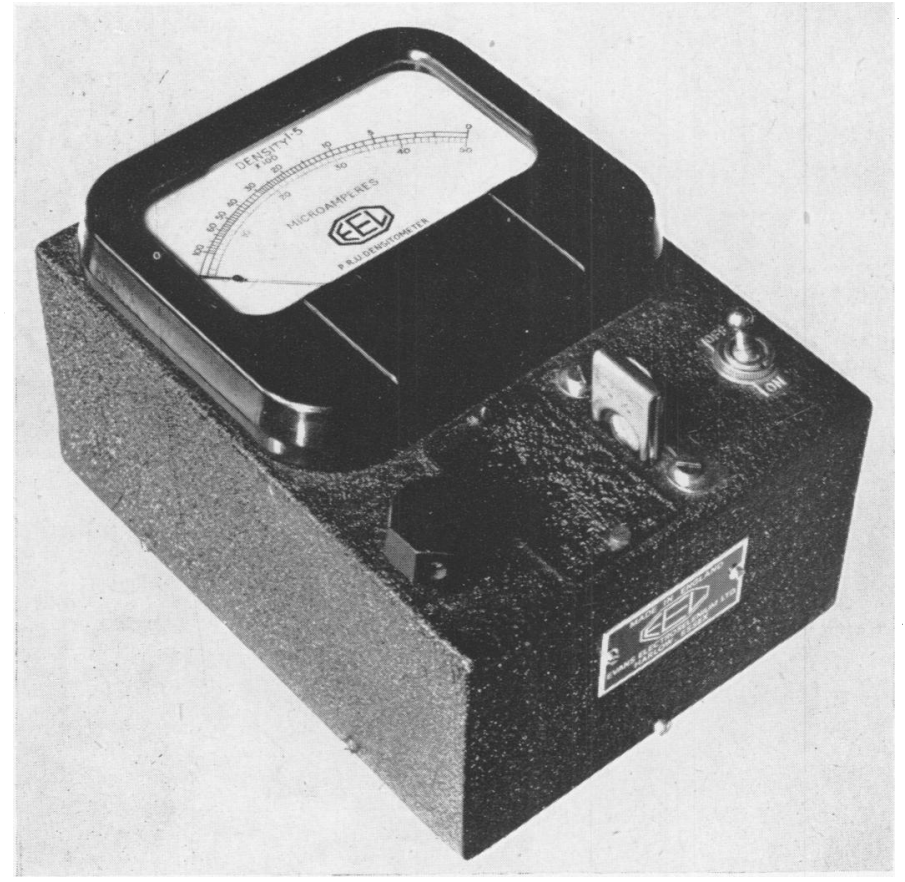

FIG. 1. - P.R.U. handpump dust-sampling outfit.

FIG. 2.-P.R.U. densitometer.

FIG. 2 


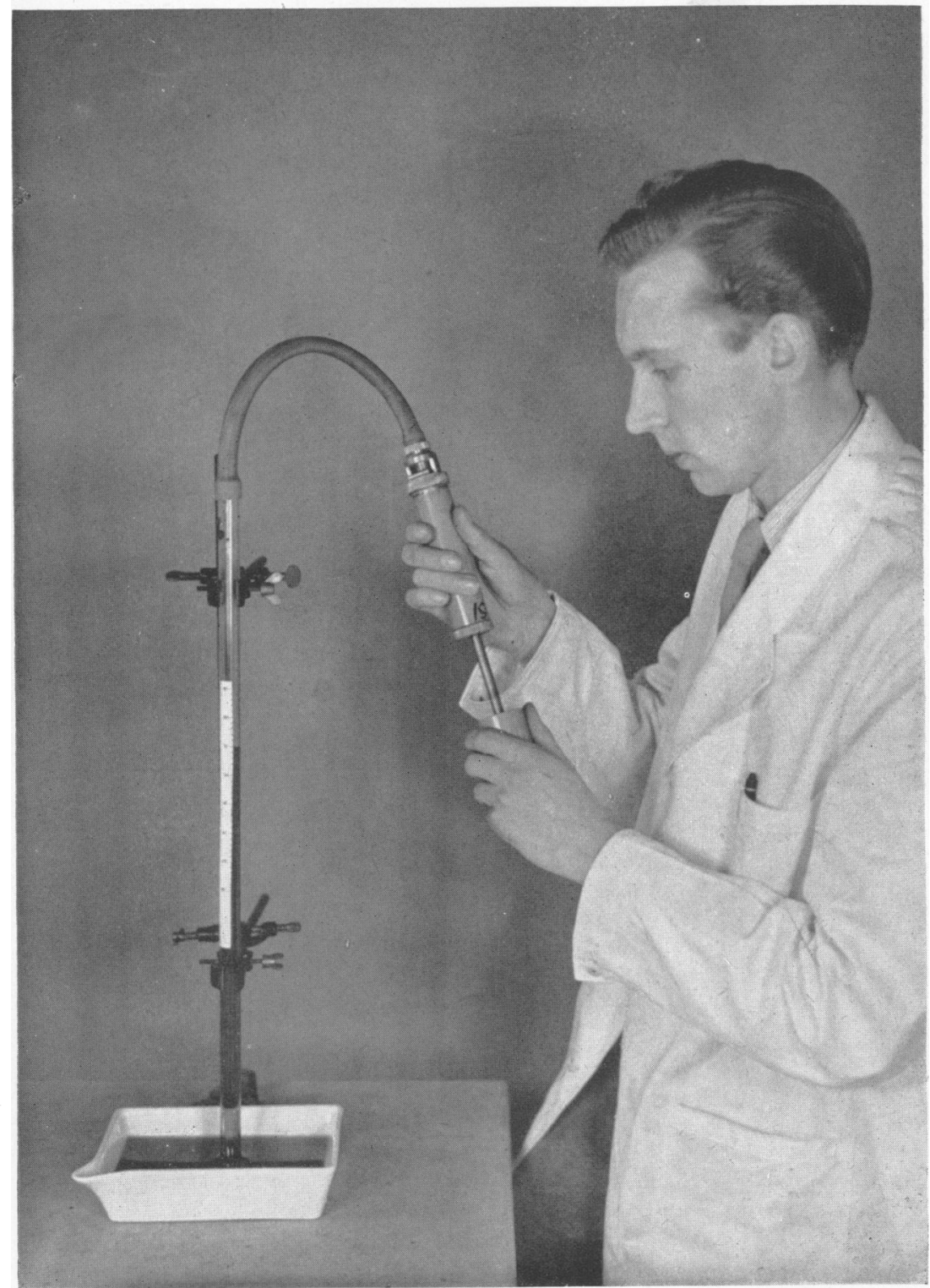

Fig. 3.-Manometer for testing hand pumps. 
is better, however, actually to measure the volume of air displaced by a single stroke. This may be done with the aid of a simple manometer (fig. 3). It consists of a straight glass tube $50 \mathrm{~cm}$. long and of internal diameter $1.8 \mathrm{~cm}$., held with its lower end just below the surface of a trough of water. The tube is graduated in c.cm. from a zero mark $0.5 \mathrm{~cm}$. above its lower end, and it is to this zero mark that the tube is inserted in the water. The pump is connected to the upper end of the tube with a short length of rubber tubing. When a stroke of the pump is made, the water rises in the tube. A pump in good working order will draw from 75 to 80 c.cm. of water into the manometer. As the air in the pump is held at a pressure less than atmospheric (by an amount equal to the height of the water in the tube) a correction to the indicated volume has to be made. For all practical purposes it is adequate to add $6 \mathrm{c} . \mathrm{cm}$. to the indicated volume.

Sampling Procedure.-A pump that has been checked, together with a box of numbered clips loaded with clean filter papers, is taken to the sampling position. Except when sampling, a spare clip loaded with a piece of filter paper is inserted in the pump to minimize accidental entry of dust and dirt into the pump. At the sampling position the first clip is inserted into the pump head, the nozzle screwed tightly down, and sampling started.

Normally, the pump is held at right angles to any ventilating air current, and a stroke made every four or five seconds. The method of sampling is to pull the pump handle out quite smartly and to hold it for three to four seconds to allow all the air to be aspirated through the filter paper and the pressure inside the pump to be brought to atmospheric. When the handle has been returned, the next stroke is made. The number of strokes taken for each sample must be counted. Although a stain of any density can be measured, greatest accuracy is obtained with stains of optical density between $0 \cdot 2$ and $0 \cdot 3$. For this reason it is advisable to vary the number of strokes according to the dust concentration. Not more than 100 strokes will generally be required for any operation in a hæmatite mine with good dust-control measures.

Assessment of Stains : The P.R.U. Densitometer.-The hand-pump method does not give an absolute measure of dust concentration, so that the amount of dust in a stain must be determined by suitable calibration with a "standard" method (see below).

The optical density of the stain is measured by means of a photo-electric densitometer (fig. 2). A clip loaded with a filter paper is pushed into a slide in the densitometer. As the clip is inserted a shutter, which normally prevents light reaching the photo-cell, is depressed and the clip comes to rest in the correct position between lamp and photo-cell. A galvanometer indicates the photo-current through the cell. The deflection is set to the maximum of the scale (zero optical density) when a clip carrying a clean piece of filter paper is inserted in the densitometer. When a stained paper is inserted the galvanometer indicates a smaller current. The difference between this and full-scale deflection gives a measure of the stain density.
Calibration.-It has been found that the general relationship between $Q$ and the number of particles producing a stain of optical density $D$ is of the form

$$
\mathrm{Q}=\mathrm{aD}^{b} \quad \text {. . . . }
$$

For coal-mine dusts $b$ averages $1 \cdot 5$, and so the P.R.U. densitometer is graduated in terms of $D^{1 \cdot 5} \times 100$. The factor 100 is introduced to eliminate zeros after the decimal point in one step of the subsequent calculation. As will be seen later, a value of 1.58 was determined for hæmatite dust. No appreciable error will occur, therefore, in using the standard scale for hæmatite dusts.

To find the calibration constant for the particular dust being sampled, it is necessary to compare simultaneous samples taken with the hand-pump and a standard method. The illustration given below shows how to connect the stain density with the result of thermal precipitator sampling.

Suppose a thermal precipitator sample gives $\mathrm{N}$ particles per c.cm., and that the optical density of the corresponding stain is $\mathrm{D}$ when $n$ strokes are taken with a hand pump of volume $v$; we may write

$$
\mathrm{N}=\frac{\mathrm{S} . \mathrm{D}^{1 \cdot 5} \times 100}{n v} \cdot . \quad \cdot
$$

where $\mathrm{S}$ is a constant. Pump-volume $v$ remains sensibly constant and for most pumps is about $82 \mathrm{c.cm}$. This value can, therefore, be taken into the calibration constant ; and we may re-write equation (2) thus

$$
\mathrm{N}=\frac{c . \mathrm{D}^{1 \cdot 5} \times 100}{n} \cdot \cdot .
$$

In practice, it is usually sufficient to take four simultaneous samples with hand pump and thermal precipitator, and to use the mean value of $c$ so obtained for all future work on the particular dust for which the calibration has been made. The value of $c$ depends naturally on the physical characteristics of the dust, and, for a given dust, on the size distribution. It would seem adequate when sampling in a hæmatite mine to determine one value for the cloud produced by blasting and another one for that from loading out and from drilling. Some values for the dust at the Florence Mine using Whatman No. 1 filter paper have been determined and are as follows :

$$
\begin{array}{lr}
\text { Blasting : } & 4.7 \times 10^{4} \\
\text { Loading : } & 10.6 \times 10^{4}
\end{array}
$$

Different values of $c$ would be obtained using different grades of paper.

Thus, when a series of hand-pump samples is obtained, the optical-densities of the stains are measured, and the value of $\mathrm{D}^{1.5} \times 100 / n$ determined for each. The number of particles per c.cm. is then simply obtained by multiplying by the appropriate value of $c$. This is a simple and rapid procedure, and once appropriate values of $c$ are available routine sampling can be done on an extended scale and estimates of the dust concentration can be quickly obtained.

Calibration of the hand-pump stains can, of course, be made in terms of any dust-sampling instrument, for 
TABLE 1

THERMAL-PRECIPITATOR SAMPLES

\begin{tabular}{|c|c|c|c|c|c|c|}
\hline & \multirow{2}{*}{$\begin{array}{c}\text { Time after shots } \\
\text { (min.) }\end{array}$} & \multirow{2}{*}{ Particles per $\mathrm{c} . \mathrm{cm}$. } & \multirow{2}{*}{$\underset{(\mu)}{\text { Median Diameter }}$} & \multicolumn{3}{|c|}{$\%$ Occurrence } \\
\hline & & & & $<0.5 \mu$ & $0.5-2 \mu$ & $2-5 \mu$ \\
\hline $\begin{array}{l}\text { After } \\
\text { shot- } \\
\text { firing }\end{array}$ & $\begin{array}{l}14 \\
20 \\
26 \\
35\end{array}$ & $\begin{array}{l}42,000 \\
36,000 \\
29,000 \\
16,000\end{array}$ & $\begin{array}{l}0.39 \\
0.32 \\
0.38 \\
0.37\end{array}$ & $\begin{array}{l}62 \\
70 \\
63 \\
63\end{array}$ & $\begin{array}{l}37 \cdot 4 \\
28 \cdot 9 \\
36 \cdot 8 \\
35 \cdot 6\end{array}$ & $\begin{array}{l}0.6 \\
1.1 \\
0.2 \\
1.4\end{array}$ \\
\hline $\begin{array}{l}\text { While } \\
\text { filling }\end{array}$ & - & 4300 & 0.23 & 85 & 15 & - \\
\hline
\end{tabular}

instance with the Owen's jet dust counter, which is used by Craw in his work in the hæmatite mines.

\section{Sampling at Florence Hæmatite Mine}

Sampling Procedure.-Samples of the dust produced by different mining operations were taken with a thermal precipitator and with hand pumps.

As a matter of routine at this mine, all mining operations are done using well-proven methods of dust-suppression. An axial flow of water is fed to the drills used for drilling the shot holes. The dust produced by shot-firing is reduced considerably by using mist-projectors which project a fine spray of water into the heading before and for some fifteen minutes after the' shots are fired. Normally two mist projectors are used, one some ten yards behind the other. During the present trials, the second mist projector was not turned on, so as to allow larger dust concentrations than normal to pass the sampling position, and for a longer time. The rock debris brought down is well watered before it is filled by shovel into trams.

The thermal precipitator was set up some ten yards outside a heading which had been driven off the roadway to a distance of about fifteen yards. Shot holes were prepared and fired. Four thermalprecipitator samples were taken of the cloud passing the sampling position at different times after the shots had been fired. One sample was also-taken during "filling-out" in a nearby heading. Handpump samples were taken during each thermal precipitator sampling period and at other times during the passage of the cloud after shot-firing. Additional hand-pump samples were taken while holes were being drilled in another heading.

Acetylene lamps are used in this mine, and all thermal precipitator records were "incinerated" to remove carbon particles (see Watson, 1936-37, p. 181). The presence of carbon particles in the stains will affect, their calibration, but, as these particles are very small, fairly large variations in the number present would not be expected to alter the calibration materially from day to day. In fact, very few were visible when the stains were examined microscopically.

Results. - The results of thermal-precipitator samples are shown in Table 1.

Hand-Pump Samples.-For the cloud reaching the thermal precipitator sampling position after shotfiring, the following empirical relationship was obtained between $D$, the optical density of the stain as measured by the P.R.U. photo-electric densitometer, and $\mathrm{N}$, the number of particles per c.cm. as given by the thermal precipitator.

$$
\mathrm{N}=4.7 \times 10^{4} . \mathrm{D}^{1.58} \times 100 / n \text {. }
$$

where $n$ is the number of strokes taken to produce the stain.

The volume of air displaced by one stroke of each pump was $82 \mathrm{c.cm}$.

It will be seen that the index of $D$, viz. 1.58 , is very close to the mean value of 1.5 that has been found to hold for coal-mines dusts.

From the single sample taken while filling out, no value of $b$ (equation 1) was obtained ; assuming it to be 1.58 , a value for $c$ of $10.6 \times 10^{4}$ was derived by comparison with the single thermal precipitator result.

Using the above experimentally determined constants, particle concentrations as shown in Table 2 were obtained from the hand-pump samples.

Discussion.-Samples were taken with the thermal precipitator at this same mine in 1935 (Watson, 1935). It is interesting to -record that a series of such samples taken in much the same relative positions as during the investigation forming the subject of this paper then gave, at fourteen minutes after firing, concentrations ranging from 31,000 to 54,000 particles per c.cm. These figures may be compared with the present result of 42,000 particles per c.cm. at the same time after firing. The 1935 results were obtained during the early days of mist projector experimentation when only one projector was used, as during the present trials. 
TABLE 2

PARTICLE CONCENTRATIONS FROM HAND-PUMP SAMPLES

\begin{tabular}{c|c|c}
\hline & $\begin{array}{c}\text { Time after } \\
\text { firing } \\
\text { (min.) }\end{array}$ & $\begin{array}{c}\text { Particles } \\
\text { per c.cm. }\end{array}$ \\
\hline \multirow{4}{*}{ After } & 1 & 15,000 \\
& 2 & 111,000 \\
shot- & 4 & 141,000 \\
firing & 7 & 190,000 \\
& 9 & 184,000 \\
& 10 & 118,000 \\
& 14 & 94,000 \\
& 20 & 45,000 \\
& 26 & 39,000 \\
& 30 & 30,000 \\
& 35 & 18,000 \\
\hline Drilling & 23 (at face) & 14,000 \\
\hline Filling out & - & 3,200 \\
\hline
\end{tabular}

TABLE 3

COMPARISON BETWEEN FINDINGS OF CRAW AND WATSON

\begin{tabular}{l|c|c}
\hline & Craw & Watson \\
\hline $\begin{array}{l}\text { Solid-place (drilling).. } \\
\text { Working-end (filling).. }\end{array}$ & $\begin{array}{c}1,782-3,980 \\
500-5,910\end{array}$ & $\begin{array}{c}2,100-3,200 \\
4,300\end{array}$ \\
$\begin{array}{l}\text { 10 minutes after blast } \\
\text { (Mist projectors }\end{array}$ & $\begin{array}{c}2,200-3,920 \\
\text { (Two mist } \\
\text { working) } \quad .\end{array}$ & $\begin{array}{c}(94,000) \\
\text { (One mist } \\
\text { projectors) }\end{array}$ \\
\hline
\end{tabular}

The full size-distributions for the 1935 trials are not available, only the median particle sizes. The range after shot-firing of 0.30 to $0.48 \mu$ may be compared with the present range of 0.32 to $0.39 \mu$.

Further comparisons can be made, with the concentrations determined with the Owens jet dustcounter (Craw, 1948) (Table 3).

The present results for drilling and for filling fall within the limits given by Craw. From a comparison of Craw's range of concentrations ten minutes after blasting and that obtained in the present trials, the second mist-projector appears to be highly effective. The single sample taken with the hand pump at the face twenty-three minutes after firing shows that the dust concentration was then much lower there than at the thermal precipitator sampling position.

\section{Conclusions}

Well-defined stains are obtained with the P.R.U. hand-pump dust-sampling apparatus when sampling . air-borne hæmatite dust. This apparatus appears to be very suitable for use in hæmatite mines, and it should appreciably shorten the labour of routine dust determinations.

Thanks are due to Dr. Craw and to the Management of the Florence Hæmatite Mine for permitting this work to be done.

\section{REFERENCES}

Craw, J. (1948) “The Control of Silicosis in the Hxmatite Mines of the North West of England." Proceedings, Conference on Silicosis, Pneumoconiosis and Dust Suppression in Mines. pp. 68-87. London. Inst. Min. Engrs. and Inst. Min. pp. $68-87$.

Watson, H. H. (1935). Unpublished report.

(1936-37). Trans. Inst. Min. Metall., 46, 155.

and Hounam, R. F. (1948). Colliery Guardian, 176, 447. 